\title{
Construção do conhecimento profissional na trajetória de professores da Educação Básica
}

\section{Construction of professional knowledge in the trajectory of Basic Education teachers}

\author{
Neusa Banhara Ambrosetti' (UNITAU) \\ Jade Moura de Godoy ${ }^{\text {ii }}$ (PMTBE/UNITAU) \\ Raissa Alexandra Lopes Duarte iii (PMSJC/UNITAU) \\ Rodrigo de Souza Mendes ${ }^{\text {iv }}$ (CIAvEx/UNITAU) \\ Rodrigo Camões Diogenes de Carvalhov (AMAN/UNITAU) \\ Valéria Aparecida de Araujo ${ }^{\text {vi }}$ (PMT/UNITAU)
}

\begin{abstract}
Resumo: Este artigo tem por objetivo analisar a construção do conhecimento profissional docente ao longo da carreira, buscando entender, na visão de professores em diferentes fases da trajetória profissional, os aspectos que consideram essenciais e os desafios nessa construção. A fundamentação teórica apoia-se em autores que vêm discutindo o aprendizado da docência como um processo que se dá ao longo da vida pessoal e profissional (HUBERMAN, 1992; TARDIF, 2002) e na perspectiva do desenvolvimento profissional docente (DAY, 2001; MARCELO, 2009). Com esse propósito, optou-se pela abordagem qualitativa de pesquisa, buscando captar o ponto de vista de docentes sobre seu percurso no aprendizado da docência. Foram entrevistados três professores atuantes em escolas públicas de educação básica, com diferentes tempos de experiência docente, ou seja, em início de carreira, meio de carreira e final de carreira. A análise dos dados indicou que os saberes experienciais são mencionados pelos professores como a fonte mais importante do conhecimento docente, o que não implica na valorização da prática dissociada da formação. Pelo contrário, os professores valorizam a formação inicial, ainda que critiquem alguns aspectos, e defendem uma formação continuada vinculada ao ambiente escolar. As colocações dos participantes desse estudo coadunam com uma percepção dos professores como sujeitos da própria prática, que elaboram seu conhecimento profissional ao longo da carreira, integrando experiências diversas na relação entre a formação e o trabalho, tendo como fonte o aprendizado com a experiência, própria e dos demais sujeitos, que, em sua atividade cotidiana, aprendem e constroem a profissão docente.

Palavras-chave: Trajetória profissional; Conhecimento profissional docente; Desenvolvimento profissional docente.
\end{abstract}




\begin{abstract}
This article aims to analyze the construction of professional teaching knowledge throughout their career, seeking to understand, in the view of teachers at different stages of their professional trajectory, the aspects they consider essential and the challenges in this construction. The theoretical foundation is supported by authors who have been discussing teaching learning as a process that takes place throughout their personal and professional life (HUBERMAN, 1992; TARDIF, 2002), from the perspective of teaching professional development (DAY, 2001; MARCELO, 2009). For this purpose, a qualitative research approach was chosen, seeking to capture the point of view of professors about their path in teaching learning. Three teachers working in public elementary schools were interviewed, with different teaching experience times, that is, in early career, mid-career and late career. The analysis of the data indicated that the experiential knowledge is mentioned by the teachers as the most important source of the teaching knowledge, which does not imply the valorization of the practice dissociated from the training. On the contrary, teachers value initial training, even though they criticize some aspects, and advocate continuing training linked to the school environment. The placements of the participants in this study are consistent with the perception of teachers as subjects of their own practice, who elaborate their professional knowledge throughout their careers, integrating different experiences in the relationship between training and work, based on learning from their own experience. and of the other subjects, who, in their daily activity, learn and build the teaching profession.
\end{abstract}

Keywords: Professional trajectory; Professional teaching knowledge; Teacher professional development.

\title{
Introdução
}

Os estudos sobre o desenvolvimento profissional dos professores vêm mostrando que o aprendizado da docência é um processo que se dá ao longo da vida pessoal e profissional, influenciado pelas experiências de formação, pelas políticas e contextos de trabalho em que os professores exercem a atividade docente (DAY, 2001). Entre os autores que discutem o aprendizado profissional nessa perspectiva, destacam-se os estudos sobre o ciclo de vida profissional dos professores, que procuram analisar o percurso dos professores ao longo da carreira. Huberman (1992) analisa inúmeras pesquisas que apontam que a carreira do magistério é constituída por várias fases ou etapas. Segundo o autor, ainda que não se possa pensar em fases ou sequências lineares, uma vez que são muitos os fatores que afetam a trajetória profissional dos docentes, o estudo do desenvolvimento pode indicar tendências que se mostram relevantes para compreender esse processo.

Nesse mesmo sentido, ao analisar o desenvolvimento dos saberes profissionais, 
Tardif (2002, p. 70) observa que "os saberes dos professores são temporais, pois são utilizados e se desenvolvem ao longo de uma carreira, isto é, ao longo de um processo temporal de vida profissional de longa duração". Essa evolução envolve aspectos pessoais e institucionais, e passa por fases e mudanças.

A compreensão do desenvolvimento profissional docente como um processo contínuo e contextualizado, que articula experiências individuais e coletivas, formais e informais, que ocorrem nos diferentes espaços de formação e de trabalho que delimitam as condições e oportunidades para esse desenvolvimento (DAY, 2001; MARCELO, 2009), nos leva a reconhecer as histórias de vida dos professores como fontes importantes na investigação do conhecimento profissional docente. Como observa Nóvoa (1992, p. 67) na investigação educacional é preciso "assegurar que a voz do professor seja ouvida, ouvida em voz alta e ouvida articuladamente". Entendemos, assim, que é relevante ouvir os professores sobre seu percurso de aprendizado profissional, procurando apreender o ponto de vista dos atores desse processo.

Neste artigo apresentamos os resultados de uma investigação que teve por objetivo analisar a construção do conhecimento profissional docente ao longo da carreira, buscando entender, na visão de professores em diferentes fases da trajetória profissional, os aspectos que consideram essenciais e os desafios nessa construção.

\section{Percurso metodológico}

Tendo em vista o propósito de investigar a construção do conhecimento profissional a partir das percepções de professores ao longo de sua trajetória, optou-se por uma abordagem qualitativa de pesquisa, buscando captar o ponto de vista de docentes em diferentes momentos da carreira. Para tanto, utilizou-se a entrevista semiestruturada como instrumento de coleta de dados. Foram entrevistados três professores, tendo como critério de escolha o fato de serem professores atuantes em escolas públicas de educação básica, com diferentes tempos de experiência docente, ou seja, em início de carreira, meio de carreira e final de carreira.

Não há consenso entre os autores sobre a duração dos períodos da carreira, em especial o período inicial, que poderia se estender até os cinco ou sete primeiros anos da docência (TARDIF, 2002). Os diversos autores que analisam esse percurso concordam que 
essa evolução não é um processo linear, que ocorre naturalmente em função do tempo, mas pode apresentar avanços e recuos, em função de condições pessoais e profissionais que delimitam a trajetória profissional, em especial os contextos do exercício profissional (TARDIF, 2002; HUBERMAN, 1992).

Neste estudo, o professor considerado em fase inicial tem cinco anos de docência, e a professora em meio da carreira tem sete anos de docência. Ambos atuam nos anos finais do ensino fundamental, lecionando, ,respectivamente, inglês e português. Sobre a formação, o professor iniciante cursou licenciaturas em Letras e Pedagogia, e atualmente faz Mestrado em Linguística. A professora em meio de carreira tem formação em Artes Cênicas e é licenciada em Letras. A professora em final de carreira possui 23 anos de experiência e atua na educação infantil. Sua formação foi no CEFAM ${ }^{1}$.

O conteúdo das entrevistas foi analisado com base nas colocações de André (1983) sobre análise de prosa, entendida pela autora como uma forma de análise do conteúdo de dados qualitativos num sentido mais amplo, que busca a compreensão dos significados dos registros das entrevistas. Considerando que o que se pretende é compreender as narrativas dos professores sobre sua trajetória profissional de modo a entendê-las no conjunto das discussões sobre a construção dos saberes e do conhecimento profissional docente, essa proposta de análise se mostrou muito adequada. Como explica André (1983), nessa abordagem não se parte de categorias previamente estabelecidas, mas os tópicos vão sendo gerados a partir do exame dos dados. Assim, embora as fases apontadas nos estudos sobre o ciclo de vida profissional fossem referências iniciais, os aspectos discutidos a seguir foram aqueles que emergiram nas leituras do material constituído pelas narrativas dos três professores, ao discorrerem sobre sua vida e sua profissão.

A análise dos dados permitiu destacar alguns aspectos que se mostram constantes nos depoimentos dos entrevistados e que apontam pontos marcantes da profissão nos diferentes momentos da carreira dos professores participantes. Emergem também na análise aspectos dissonantes, que podem ser compreendidos ao considerar os diferentes momentos na evolução da profissão docente.

Na análise apresentada, a seguir, são apresentados os resultados dessa

${ }^{1} \mathrm{O}$ Centro Específico de Formação e Aperfeiçoamento do Magistério (CEFAM) foi uma experiência diferenciada de formação docente no ensino médio. O curso tinha duração de quatro anos em horário integral, e oferecia bolsas de estudo aos alunos para frequentarem as aulas. 
compreensão, com foco na percepção dos professores entrevistados sobre a construção do conhecimento profissional em dois momentos principais: os anos iniciais da docência e a continuidade na constituição desses saberes, ao longo da carreira.

\section{O início da docência: desafios e aprendizado}

Fruto da análise qualitativa dos dados levantados através das entrevistas sobre o olhar dos participantes a respeito da trajetória profissional, podemos observar que as opiniões dos professores da rede básica, em diferentes estágios, apresentam aspectos em comum e, por vezes, divergem.

Os dados mostram que os entrevistados vivenciaram esse período de maneiras diversas, o que pode ser relacionado às diferentes condições da formação inicial, da época do início profissional e dos contextos de atuação dos entrevistados.

Ao discorrer sobre seus anos iniciais na carreira, a professora experiente, relata que "os primeiros anos foram maravilhosos, estava no auge, cheia de energia e saúde, tanto física quanto mental e me dedicava ao máximo". Da mesma forma, a professora menciona que a realidade encontrada não foi diferente das suas expectativas:

Naquele tempo tinha crianças mais disposta a aprender e os pais também respeitavam mais, eram mais compreensivos. Não foi uma realidade tão diferente da que eu esperava. Tinha dificuldade sim, como todo ensino. Essa parte de recursos, sempre teve essa falta, sempre trabalhei na rede pública, então tinha essa dificuldade. Mas não era tão fora do que eu imaginava. (Professora experiente).

Essa narrativa revela a entrada na docência como um período de relativa tranquilidade, semelhante à etapa descrita por Huberman (1992) como de descoberta, que se traduz no entusiasmo por sentir-se parte de um grupo profissional, levando o professor a comprometer-se com a profissão e a desejar permanecer nela.

Já o professor iniciante e a professora em meio de carreira revelam uma visão traumática de dias conturbados, descrevendo um período desafiador:

Os primeiros anos foram desafiadores, muitas vezes eu questionei se estaria no lugar certo e na profissão certa, pois a realidade é bem diferente do que nós idealizamos na faculdade. (Professora em meio de carreira).

Eu havia acabado de sair da graduação [...] e era uma escola que estava localizada em um bairro em uma cidade bastante vulnerável, uma população bastante carente, salas lotadas e tudo isso contribuiu, até hoje 
posso até falar que naquela época contribuiu para uma experiência um tanto traumática. (Professor em Início de Carreira).

Observa-se que a realidade encontrada foi, na visão desses professores, muito diferente do que esperavam. A vida no "chão da sala", chegou em forma de diferenças sociais, salas lotadas, falta de engajamento da comunidade, falta de motivação dos alunos e de alguns colegas de trabalho. Pode-se entender esses relatos como um período descrito por Huberman (1992) como de sobrevivência, quando o professor é confrontado com os desafios e complexidade da atividade docente e constata a distância entre a realidade idealizada e as condições encontradas no exercício da profissão. Essa situação tem sido caracterizada também pela expressão "choque com o real" cunhada por Vennman (1984, apud TARDIF, 2002, p. 85) para referir-se a esse confronto do professor novato com a dura realidade do exercício de uma profisssão complexa, que deve ser dominada por ele.

Uma questão que parece fazer diferença quando os participantes resgatam as experiências vivenciadas é o tempo decorrido desde as experiências iniciais na docência. A professora experiente ressalta a diferença entre a realidade atual e o contexto social de outra época, onde os alunos e familiares eram mais respeitosos com os professores e a escola mais valorizada. Pode-se considerar que esse relato remete a um período afastado no tempo, permeado hoje pela memória afetiva. Já para os professores com menor tempo na docência esse período inicial traz a memória de relações mais difíceis, em condições desfavoráveis de trabalho.

Essas diferentes perspectivas podem ser atribuídas aos diferentes contextos de atuação dos professores, uma vez que o trabalho na educação infantil, com crianças pequenas, tende a ser menos sujeito a tensões do que aquele dos professores que trabalham com jovens adolescentes. No entanto, como ressalta Huberman (1992), uma contingência a ser levada em conta no estudo do ciclo de vida profissional é o funcionamento da memória. $\mathrm{O}$ autor lembra que a recordação do passado é uma recriação dos acontecimentos vividos, ou seja, ao narrar reinterpretamos as experiências e damos sentido ao passado, à luz da trajetória percorrida até o presente.

Outro aspecto destacado pelos entrevistados refere-se à dimensão relacional da docência. O professor em início de carreira destaca os desafios "relacionados a questões inter-relacionais, relações sociais que a escola proporciona", e detalha essa situação:

[...] a falta de participação, falta de engajamento da comunidade, falta de 
motivação que meus alunos tinham dentro da aula e falta de crenças que os agentes escolares tinham em relação a própria escola era de saltar dos olhos, gritante e isso me incomodava muito na época.(Professor em início de carreira).

Observa-se que o professor não situa esses desafios apenas nas relações com os alunos, mas destaca também a compreensão dos agentes escolares sobre o papel da escola como um elemento fundamental na construção dessas relações.

A professora em meio de carreira destaca a diversidade de situações com as quais o professor se depara na sala de aula:

O maior desafio foi lidar com as diferentes realidades dos alunos, como sempre trabalhei no ensino público me deparei com diversas situações, como: alunos que não tinham família, outros eram usuários de drogas e fazia parte do tráfico, alunos com grandes dificuldades de aprendizado, alunos de inclusão e outros que tinham uma estrutura familiar muito boa. Imaginem juntar todas essas realidades dentro de uma sala com 30 a 40 alunos? Para aprender a lidar com todas essas situações foi bastante desafiador. (Professora em meio de carreira)

Os depoimentos revelam um aspecto essencial do trabalho docente, ou seja, é uma atividade que se realiza num contexto de interações humanas. Como ressaltam Tardif e Lessard (2005, p. 31) "ensinar é trabalhar com seres humanos, sobre seres humanos, para seres humanos" (grifos dos autores). Ainda segundo os autores, deve-se considerar que a docência acontece numa escola, um espaço social organizado, com normas e regras formais e informais, que envolvem e delimitam as relações profissionais que ocorrem nesse espaço.

Assim, o trabalho dos professores é permeado por questões de valores, relações de poder, dilemas e contradições inerentes a uma profissão complexa, construída nas relações cotidianas com os alunos e colegas de trabalho, exercida em contextos que estruturam e afetam esse trabalho.

Apesar dos desafios e dificuldades destacadas no início profissional, os entrevistados convergem quando se referem à fase inicial da docência como um período de grande aprendizado profissional.

Os primeiros 3 anos da minha carreira foram, eu acredito, o momento em que eu mais aprendi, que eu mais amadureci como profissional; claro que o amadurecimento e aprendizagem sempre acontecem, independente de ter ou não desafios, entretanto foram os anos que mais tive desafios, foram os anos que mais aprendi.(Professor em início de carreira)

Nesse aprendizado, destacam o apoio dos colegas, gestores e familiares, que 
segundo eles foi fundamental para o desenvolvimento dos profissionais que são hoje.

Tive bastante apoio dos próprios colegas e na gestão escolar, construí uma relação muito forte com eles e isso me ajudou muito, nos ensinamentos, ao saber lidar com os conflitos e desafios dentro de sala de aula, e principalmente na parte burocrática que é bem difícil no início.(Professora em meio de carreira)

Os relatos dos entrevistados sobre as experiências iniciais na docência vão ao encontro das colocações de Tardif (2002), quando afirma que é no início da carreira que são constituídas as bases do conhecimento profissional docente. Ainda segundo o autor, nesse percurso são muito importantes os conhecimentos compartilhados com os pares e os conselhos de colegas mais experientes.

Os entrevistados foram aos poucos superando as dificuldades e incertezas desse período inicial, dando lugar a uma sensação de maior segurança e identificação com a docência, situação que pode ser entendida como uma fase de estabilização, caracterizada por Huberman (1992, p. 40) como um período em que o professor passa a sentir-se membro do corpo profissional, "passa a ser professor, quer aos seus olhos, quer aos olhos dos outros" e adquire um sentimento crescente de competência pedagógica.

Segundo Tardif (2002), esse domínio progressivo do trabalho e a maior clareza em relação aos próprios limites e possibilidades permitem também maior abertura para a continuidade no aprendizado da profissão.

\section{A construção do conhecimento profissional ao longo da carreira}

Partindo do pressuposto de que as diferentes situações que o professor precisa enfrentar diariamente exigem um conhecimento complexo, que deve ser compreendido na relação com as condições de trabalho, o tempo, o espaço, os alunos e os demais agentes que interagem no cotidiano escolar, buscamos compreender como os participantes do estudo percebem o desenvolvimento do conhecimento profissional na continuidade da carreira.

Os professores entrevistados valorizam diferentes fontes de saberes na construção do conhecimento profissional. Um aspecto em que as perspectivas divergem é quando se referem às contribuições da formação inicial para o exercício da docência.

A professora experiente relata que cursou o antigo CEFAM, experiência que segundo 
ela foi essencial para sua atuação profissional:

A formação inicial foi primordial, onde mais me dediquei, até por ser mais nova, tive mais tempo. Fiquei quatro anos, no que antigamente era o CEFAM. Hoje não existe mais, infelizmente, quatro anos, período integral, tive ótimos professores que eu levo até hoje na minha vida profissional.

Os professores com menos tempo de carreira também valorizam a formação inicial, mas apontam que a formação na universidade não os preparou para lidar com a realidade da sala de aula, como se observa no depoimento da professora em meio de carreira:

A formação inicial foi primordial e com ela vieram dois elementos importantes para mim que são: o domínio do conteúdo e o domínio da sala de aula. (Professora em meio de carreira)

Apesar dessa opinião favorável, ela ressalvaque esses conhecimentos não foram suficientes para lidar com a realidade cotidiana:

Foi totalmente diferente. Lidar com a realidade da rede pública é muito difícil porque na faculdade nós aprendemos a teoria e quando chegamos na sala de aula reaprendemos na prática. (Professora em meio de carreira)

O professor em início de carreira tem uma visão mais crítica sobre o curso de licenciatura:

Sim, a formação inicial trouxe alguns elementos importantes para a atuação docente, ele tem proporcionado a mim como professor certas concepções que foram de fato importantes para a minha prática em sala de aula; entretanto eu senti falta de teoria na minha graduação, como eu disse a primeira foi bastante prática, e a segunda que eu fiz também embora trouxesse um pouquinho mais de embasamento teórico, ele era bem desligado da prática, então hoje em dia eu acredito que a própria grade curricular do Ensino Superior precisava ser revista para ajudar que esse jovem professor assim como eu conseguisse se formar e que essa formação conversasse em certas medidas com os contextos variados no qual os professores vão agir, mas eu creio que a graduação precisa empoderar, formar esse professor para atuação. (Professor em início de Carreira).

Embora a afirmação do professor iniciante fale de "uma formação mais prática e menos teórica", subentende-se que a crítica à falta de formação teórica seria voltada à formação pedagógica, que não teria proporcionado um conhecimento articulado à realidade da sala de aula, possibilitando uma prática fundamentada e reflexiva. Aparentemente contraditórias em relação ao espaço da teoria no currículo, as opiniões desses dois professores convergem no sentido de que não se sentiram preparados para o ensino. 
Essas posições remetem às relações entre teoria e prática na construção do conhecimento profissional docente. Como ressalta Tardif (2002), a prática docente não é um espaço de aplicação de saberes teóricos, mas deve ser entendida como um espaço de produção e transformação de saberes, o que implica reconhecer o professor como "um sujetito do conhecimento, um ator que desenvolve e possui sempre teorias, conhecimento e saberes de sua própria ação" (TARDIF, 2002, p. 235).

Os depoimentos dos participantes desse estudo corroboram essa compreensão da prática como espaço de produção de conhecimento. Todos consideram que a formação inicial ofereceu, em maior ou menor dimensão, elementos para sua atuação profissional. Valorizam o conhecimento teórico, mas destacam a importância da prática cotidiana como fonte de aprendizado da docência.

Ao refletir sobre sua trajetória, a professora mais experiente reconhece a importância dos estudos, mas ressalta a importância da prática como fonte principal dos saberes profissionais, como se mostra no extrato a seguir:

Muito estudo e pesquisa, mas acima de tudo na prática. Não tem maior aprendizado, não há uma construção do conhecimento, sem lidar com a prática. A teoria é muito boa, os estudos, mas a prática que foi a definição da minha carreira, para evolução. (Professora em final de carreira).

A professora em meio de carreira coloca que seu conhecimento profissional é plural, adquirido nas diferentes situações formativas e, principalmente, com a experiência. Destaca ainda a importância da interação com os colegas docentes com a gestão e principalmente na sala de aula com os alunos.

Pensando na minha trajetória profissional, o conhecimento veio de muito estudo e principalmente da experiência do dia a dia na educação. Temos que estar em constante formação porque o mundo se transforma, até para conseguirmos acompanhar a evolução dos alunos. Portanto, acredito que as experiências e o estudo são fundamentais para a construção do nosso conhecimento profissional. (Professora emmeio de carreira).

Nestas falas evidencia-se a importância dos saberes da prática para os participantes deste estudo. No entanto, essa prática não é entendida como um saber desvinculado da teoria, mas como um conhecimento amplo, que mobiliza e integra os saberes de diferentes fontes. Os relatos vão ao encontro da posição de Tardif (2002, p. 36), quando define o saber docente como "um saber plural, formado pelo amálgama, mais ou menos coerente, de saberes oriundos da formação profissional e de saberes disciplinares, curriculares e 
experienciais".

O autor destaca a importância dos saberes experienciais como núcleo do saber docente, decorrentes da retradução, pelo professor, dos demais saberes, submetidos às contingências da prática. Nessa perspectiva, os saberes experienciais são saberes que se constroem a partir da experiência, mas que não se resumem somente a ela (TARDIF, 2002).

Ainda segundo Tardif (2002), a imprevisibilidade que acompanha o trabalho docente resulta em um constante movimento de transformação e flexibilidade da ação e, consequentemente, dos saberes. Nesse sentido, torna-se necessário um saber que possibilite ao professor lidar com as situações imprevistas da prática. Logo, é em meio aos impasses e desafios do trabalho, no confronto direto com a profissão, que os saberes experienciais se originam e se consolidam.

Vale ressaltar que o os saberes experienciais são saberes sociais, uma vez que não são construídos isoladamente, mas em "contextos relacionais, sociais e culturais" (VAILLANT; MARCELO, 2012, p. 43), a partir das relações que os professores estabelecem com os demais atores escolares. É também na e a partir dasocialização profissional que o saber da experiência garante sua legitimidade. Algo evidenciado na fala do professor iniciante, quando diz que:

O conhecimento a gente constrói nas relações sociais, na interação que a gente tem voltada para o nível mais dialético, então a gente constrói conhecimento, se desenvolve por meio das relações, eu tenho essa percepção [...] então a Instituição Escola tem sido o local no qual eu tenho desenvolvido conhecimento. Voltado para a escola enquanto local de trabalho, ela deveria também de fato ser um local onde o docente pudesse construir conhecimento e ter sua formação continuada, entretanto não é o que vem acontecendo, até o próprio HTPC hoje ele é um momento mais informativo do que formativo para ser bem sincero não é o que deveria ser, mas é o que tem sido. (Professor Início de Carreira).

A posição do professor, ao salientar o papel da escola como espaço da formação, e não apenas do trabalho docente, mostra uma compreensão do aprendizado profissional que identifica-se com as análises de Canário $(1998$, p. 9) quando destaca que a escola tem sido vista, numa concepção redutora, como "um sítio onde os alunos aprendem e os professores ensinam" (grifos do autor). Canário questiona essa perspectiva simplista, que desconsidera o papel da escola como espaço privilegiado na construção do conhecimento profissional, lembrando que a escola é o lugar onde os professores aprendem a sua profissão. 
Os depoimentos dos professores reafirmam essa visão. A importância da formação continuada foi evidenciada nas três entrevistas, onde os participantes compartilharam a mesma opinião, de que a formação em serviço é um processo contínuo, permanente e vinculado à prática.

A descrição da professora em meio de carreira sobre seu percurso formativo indica essa compreensão, como se mostra no extrato a seguir:

Acho que toda formação, todo conhecimento que você busca em forma de pesquisaou em cursos, tudo serve para o seu conhecimento, e nada é em vão. Minha formação inicial antes de ingressar na área de educação foi em Artes Cênicas e tem sido primordial para meu diálogo com os alunos, mas tive muitas formações pela própria prefeitura, o que sempre me ajudou em sala de aula, porque sempre há troca de experiências com outros profissionais quando estamos em formação [...] nos faz enxergar formas diferentes de se trabalhar em sala de aula além de estar renovando o docente para algo novo, um olhar novo.

Os depoimentos dos professores sobre seu aprendizado da docência podem ser comprendidos na perspectiva do desenvolvimento profissional, entendido por Marcelo (2009, p. 10), como

um processo, que pode ser individual ou colectivo, mas que se deve contextualizar no local de trabalho do docente - a escola - e que contribui para o desenvolvimento das suas competências profissionais através de experiências de diferente índole, tanto formais como informais.

Essa concepção permite entender a formação docente como um aprendizado contínuo, vinculado ao contexto de trabalho dos professores, superando a justaposição entre formação inicial e continuada que tem caracterizado o percurso formativo dos docentes.

\section{Considerações Finais}

Os dados desse estudo nos levam a considerar o desenvolvimento profissional dos professores como um processo ao mesmo tempo individual e coletivo,que está intimamente relacionado aos saberes provenientes de sua própria experiência na profissão, na sala de aula e na escola, através da socialização com os pares.

A análise das entrevistas dos três professores indicou que os saberes experienciais são mencionados por todos eles como a fonte mais importante do conhecimento docente, 
independente do momento do ciclo de vida profissional que se encontram. Isto não implica, no entanto, na valorização da prática dissociada da formação. Pelo contrário, os professores defendem uma formação continuada vinculada ao ambiente escolar. Consideram ainda que esta formação foi, e é essencial para seu desenvolvimento enquanto docentes e deve ser um objetivo permanente durante a carreira.

Os dados confirmaram que a formação profissional é um processo contínuo e permanente, começando antes da escolha da profissão, através de influências de pessoas próximas e pelos próprios professores. Indicam também a importância do espaço escolar como espaço de aprendizado da docência. Os relatos mostraram histórias de vida singulares, porém permeadas pela experiência coletiva, construídas em contextos escolares diversos, que delimitam as condições do aprendizado profissional desses docentes, e que podem oferecer maiores oportunidades ou dificultar esse processo.

As colocações dos participantes desse estudo coadunam com uma percepção dos professores como sujeitos da própria prática, que elaboram seu conhecimento profissional ao longo da carreira, integrando experiências diversas na relação entre a formação e o trabalho, tendo como fonte o aprendizado com a experiência, própria e dos demais sujeitos, que, em sua atividade cotidiana, aprendem e constroem a profissão docente.

\section{Referências}

ANDRÉ, Marli. Texto, contexto e significados: algumas questões na aanálise de dados qualitativos. Cadernos de Pesquisa, n. 45, p. 66-71, maio, 1983.

CANÁRIO, Rui. Escola, o lugar onde os professores aprendem. Psicologia da Educação, v. 6, p. 9-27, 1998. Disponível em:https://revistas.pucsp.br/psicoeduca/article/view/42874/28552

DAY, Christopher. Desenvolvimento profissional de professores:os desafios da aprendizagempermanente. Porto: Porto Editora, 2001.

HUBERMAN, Michael. O ciclo de vida profissional dos professores. In: Vidas de professores. Porto: Porto Editora, 1992.

MARCELO, Carlos. Desenvolvimento Profissional Docente: passado e futuro. Sísifo.

Revista das Ciências da Educação, n. 08, p. 7-22, jan./abr. 2009. Disponível em: <http://www.unitau.br/files/arquivos/category_1/MARCELO_Desenvolvimento_Profissiona I_Docente_passado_e_futuro_1386180263.pdf>.Acesso em: 25 ago. 2020. 
NÓVOA, António. Os professores e as histórias da sua vida. In: NÓVOA, António. Vidas de professores. Porto: Porto Editora, 1992.

SHULMAN, Lee. Conhecimento e ensino: fundamentos para a nova reforma. Cadernos Cenpec. São Paulo, v.4, n.2, p.196-229, dez. 2014.

TARDIF, Maurice. Saberes docentes e formação profissional. Petrópolis, Rio de Janeiro: Vozes, 2002.

TARDIF, Maurice.; RAYMOND, Danielle. Saberes, tempo e aprendizagem do trabalho no magistério. Educação \& Sociedade [online]. 2000, vol.21, n.73, pp.209-244. Disponível em:<https://www.scielo.br/scielo.php?pid=S0101- 73302000000400013\&script=sci _abstract\&tlng=pt>Acesso em: 25 ago. 2020.

TARDIF, Maurice.; LESSARD, Claude. O trabalho docente: elementos para uma teoria da docência como profissão de interações humanas. Petrópolis: Vozes, 2005.

VAILLANT, Denise.; MARCELO, Carlos. Ensinando a ensinar: as quatro etapas de uma aprendizagem. Curitiba: Ed. UTFPR, 2012.

i Docente do Mestrado profissional em Educação da Universidade de Taubaté; Doutora em Psicologia da Educação pela PUCSP, com Pós-doutorado em Psicologia da Educação pela mesma instituição.

E-mail: $\underline{\text { nbambrosetti@gmail.br }}$

ii Professora de Educação Básica da Rede Municipal de Tremembé-SP; Pós-graduada em Transtorno do Espectro Autista pelo Centro Universitário Celso Lisboa (UCL) - RJ, em parceria com a CBI of Miami (EUA-Flórida); Mestranda em Educação pela Universidade de Taubaté, (UNITAU).

E-mail:jadee_moura@outlook.com

iii Professora de Educação Básica da Rede Municipal de São José dos Campos-SP; Pós-Graduada em Arte Educação pela Universidade de São Paulo (USP); Mestranda em Educação pela Universidade de Taubaté (UNITAU).

E-mail: $\underline{\text { raissa.alexandras2@gmail.com }}$

iv Coordenador pedagógico no Centro de Instrução de Aviação do Exército (CIAvEx)-SP; PósGraduado em Educação pelo Centro de Estudos de Pessoal (CEP/FDC); Mestrando em Educação pela Universidade de Taubaté (UNITAU).

E-mail: mnd.rodrigo@gmail.com

$\checkmark$ Coordenador pedagógico na Academia Militar das Agulhas Negras (AMAN)-RJ; Pós-Graduado em Educação pelo Centro de Estudos de Pessoal (CEP/FDC); Mestrando em Educação pela Universidade de Taubaté (UNITAU).

E-mail: rodrigocamoesdiogenes@gmail.com

vi Professora formadora da Rede Municipal de Taubaté-SP; Licenciada em Pedagogia pela Universidade Metropolitana de Santos - UNIMES; Mestranda em Educação pela Universidade de Taubaté (UNITAU).

E-mail: valeria_araujo.m@hotmail.com 